\title{
Development of a Radial Deconsolidation Method
}

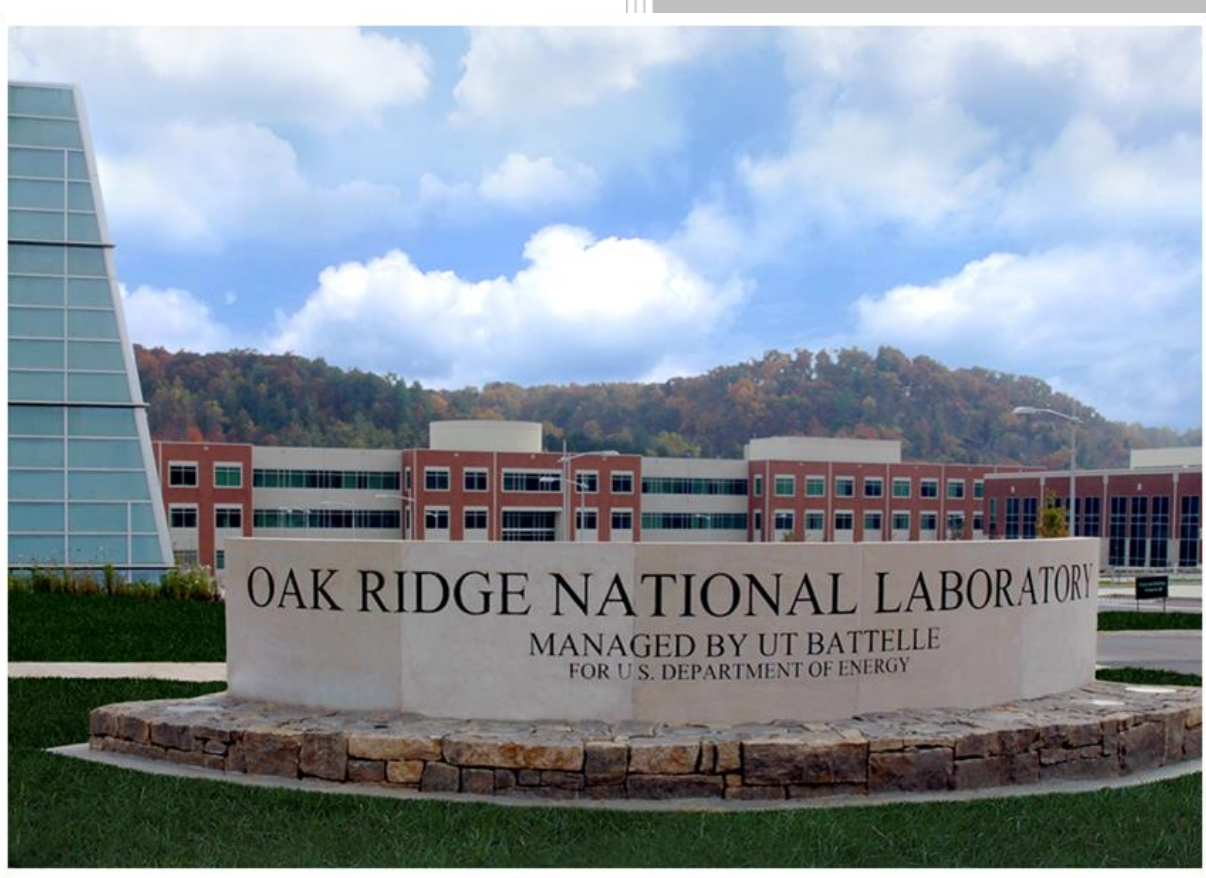

Grant Helmreich Fred C. Montgomery John D. Hunn

December 2015 
DOCUMENT AVAILABILITY

Reports produced after January 1, 1996, are generally available free via US Department of Energy (DOE) SciTech Connect.

Website http://www.osti.gov/scitech/

Reports produced before January 1, 1996, may be purchased by members of the public from the following source:

National Technical Information Service

5285 Port Royal Road

Springfield, VA 22161

Telephone 703-605-6000 (1-800-553-6847)

TDD 703-487-4639

Fax 703-605-6900

E-mail info@ntis.gov

Website http://www.ntis.gov/help/ordermethods.aspx

Reports are available to DOE employees, DOE contractors, Energy Technology Data Exchange representatives, and International Nuclear Information System representatives from the following source:

Office of Scientific and Technical Information

PO Box 62

Oak Ridge, TN 37831

Telephone 865-576-8401

Fax 865-576-5728

E-mail reports@osti.gov

Website http://www.osti.gov/contact.html

This report was prepared as an account of work sponsored by an agency of the United States Government. Neither the United States Government nor any agency thereof, nor any of their employees, makes any warranty, express or implied, or assumes any legal liability or responsibility for the accuracy, completeness, or usefulness of any information, apparatus, product, or process disclosed, or represents that its use would not infringe privately owned rights. Reference herein to any specific commercial product, process, or service by trade name, trademark, manufacturer, or otherwise, does not necessarily constitute or imply its endorsement, recommendation, or favoring by the United States Government or any agency thereof. The views and opinions of authors expressed herein do not necessarily state or reflect those of the United States Government or any agency thereof. 
Fusion and Materials for Nuclear Systems Division

\title{
DEVELOPMENT OF A RADIAL DECONSOLIDATION METHOD
}

\author{
Grant Helmreich \\ Fred C. Montgomery \\ John D. Hunn \\ Date Published: December 2015 \\ Work sponsored by \\ US DEPARTMENT OF ENERGY \\ Office of Nuclear Energy - Advanced Reactor Technologies \\ under the \\ Advanced Gas Reactor Fuel Development and Qualification Program
}

Prepared by

OAK RIDGE NATIONAL LABORATORY

Oak Ridge, TN 37831-6283

managed by

UT-BATTELLE, LLC

for the

US DEPARTMENT OF ENERGY

under contract DE-AC05-00OR22725 



\section{CONTENTS}

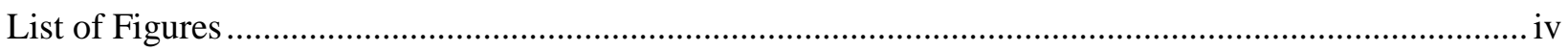

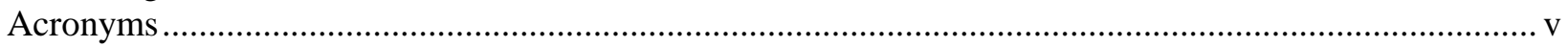

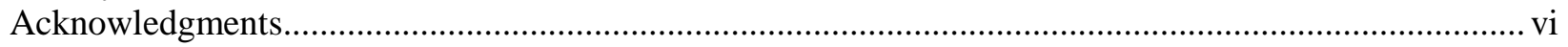

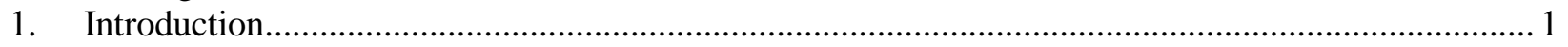

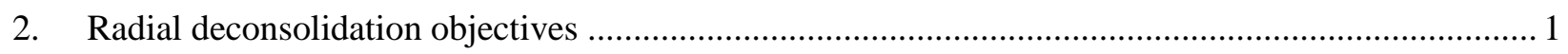

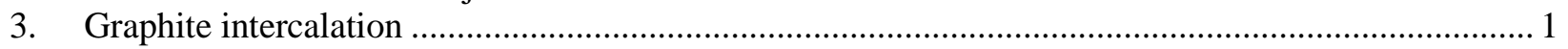

4. Deconsolidation apparatus and process development.............................................................. 2

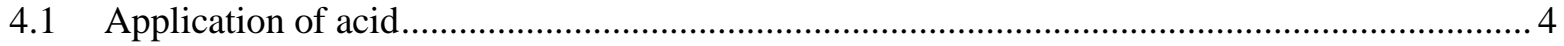

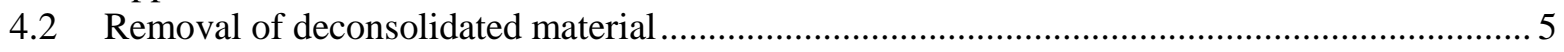

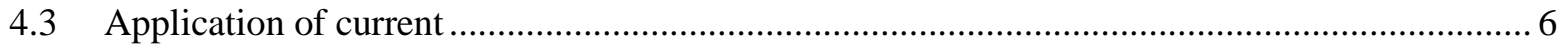

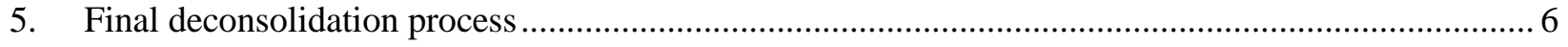

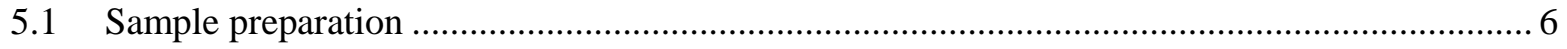

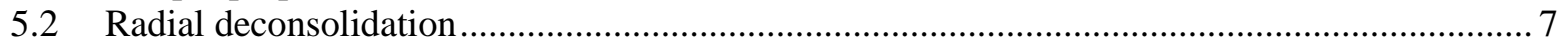

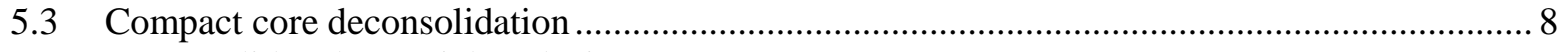

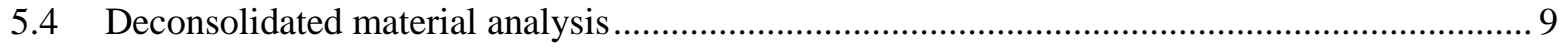

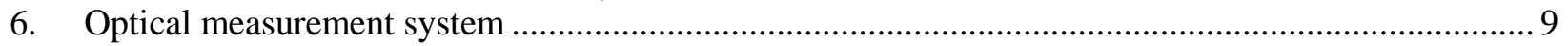

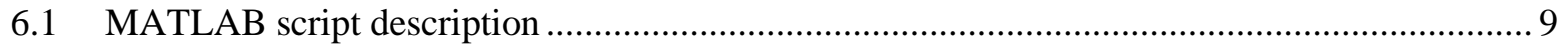

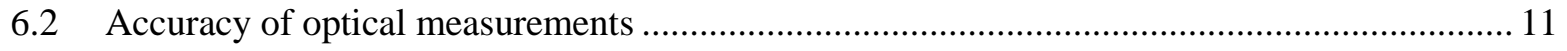

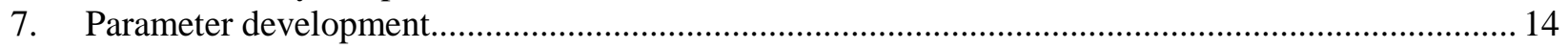

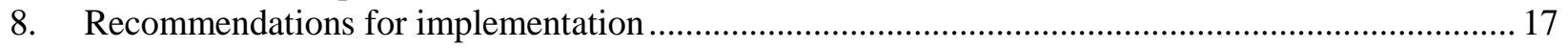

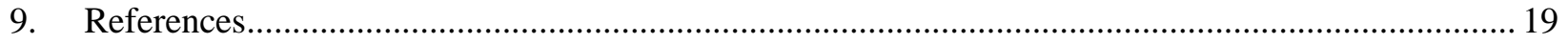




\section{LIST OF FIGURES}

Figure 1. Radial deconsolidation rig originally used for fuel pebble deconsolidation.............................. 3

Figure 2. Compact epoxied to mounting rod in centering vee-block................................................... 3

Figure 3. Schematic of the stream deconsolidation method. ............................................................... 4

Figure 4. Early deconsolidation test using a static bath with an insulated mesh screen. ........................... 4

Figure 5. Deconsolidated material removal screen held in place against compact prior to

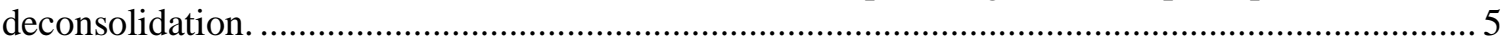

Figure 6. Compact mounted on the final apparatus ready for deconsolidation......................................... 7

Figure 7. Setup for axial deconsolidation of the compact core ............................................................. 8

Figure 8. User selected fiducial mark (left), starting rod contour (center), and starting compact

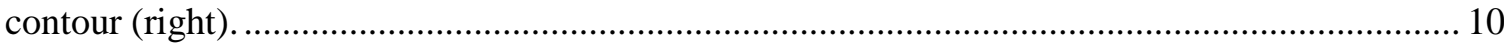

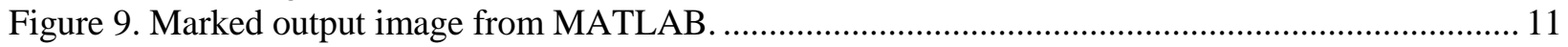

Figure 10. Rotational dependence of apparent compact radius on rotation angle (vertical spread is due to radial deconsolidation and stochastic measurement error). ............................................. 12

Figure 11. Gradual reduction of compact radius over time due to deconsolidation (vertical spread is due to axial runout and stochastic measurement error).......................................................... 12

Figure 12. Reduction in compact radius over time smoothed out by averaging over each full

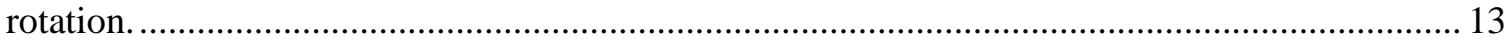

Figure 13. Compact radius during initial deconsolidation demonstrating surface flaking effect. ............. 13

Figure 14. Size distribution of deconsolidated matrix from tests varying current with $6 \mathrm{~N}$ nitric

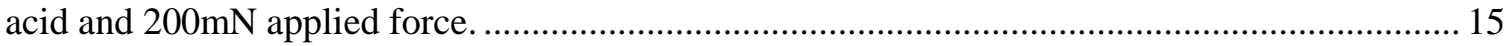

Figure 15. Size distribution of deconsolidated matrix from tests varying current with $4 \mathrm{~N}$ nitric

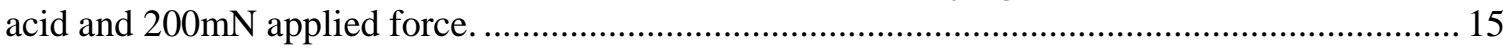

Figure 16. Size distribution of deconsolidated matrix from tests varying force with $4 \mathrm{~N}$ nitric acid

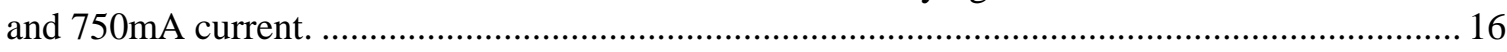

Figure 17. Residual matrix material on TRISO particles deconsolidated with variable brushing

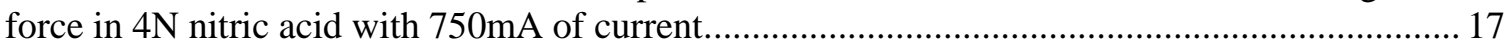

Figure 18. Rate of deconsolidation in $4 \mathrm{~N}$ nitric acid with $750 \mathrm{~mA}$ of current with variable brushing force. 


\section{ACRONYMS}

AGR Advanced Gas Reactor Fuel Development and Qualification Program

ATR

DTF

INL

OPyC

ORNL

Advanced Test Reactor (at INL)

Designed to Fail

Idaho National Laboratory

Outer pyrolytic carbon (layer)

Oak Ridge National Laboratory

TRISO Tristructural isotropic (coated particles) 


\section{ACKNOWLEDGMENTS}

This work was sponsored by the U.S. Department of Energy, Office of Nuclear Energy, through the Idaho National Laboratory Advanced Reactor Technologies Technology Development Office as part of the Advanced Gas Reactor Fuel Development and Qualification Program. 


\section{INTRODUCTION}

A series of experiments have been initiated to determine the retention or mobility of fission products ${ }^{*}$ in AGR fuel compacts [Petti, et al. 2010]. This information is needed to refine fission product transport models. The AGR-3/4 irradiation test involved half-inch-long compacts that each contained twenty designed-to-fail (DTF) particles, with $20-\mu \mathrm{m}$ thick carbon-coated kernels whose coatings were deliberately fabricated such that they would crack under irradiation, providing a known source of postirradiation isotopes. The DTF particles in these compacts were axially distributed along the compact centerline so that the diffusion of fission products released from the DTF kernels would be radially symmetric [Hunn, et al. 2012; Hunn et al. 2011; Kercher, et al. 2011; Hunn, et al. 2007]. Compacts containing DTF particles were irradiated at Idaho National Laboratory (INL) at the Advanced Test Reactor (ATR) [Collin, 2015]. Analysis of the diffusion of these various post-irradiation isotopes through the compact requires a method to radially deconsolidate the compacts so that nested-annular volumes may be analyzed for post-irradiation isotope inventory in the compact matrix, TRISO outer pyrolytic carbon (OPyC), and DTF kernels. An effective radial deconsolidation method and apparatus appropriate to this application has been developed and parametrically characterized.

\section{RADIAL DECONSOLIDATION OBJECTIVES}

The ultimate objective for the radial deconsolidation process is to provide reliable post-irradiation isotope distribution data. To accomplish this, systematic deconsolidation of the compact is required. A series of qualifications were determined to define an appropriate deconsolidation approach. First, material removal from the compact must occur in uniform radial sections and process measurements of material removal must be sufficiently accurate to assign measured fission products within each deconsolidated fraction to their source volume. The uniformity and accuracy necessary to meet this objective may be considered in terms of the uncertainty inherent in the eventual measurement of fission product inventories, which is typically $\sim 10 \%$. Second, the process must be able to cleanly separate particles from the matrix. This means the process must be aggressive enough to produce clean particles free of residual matrix, yet gentle enough to ensure particles remain intact. In addition, the deconsolidated matrix debris should ideally be uniformly fine to allow for easy separation from both TRISO particles and intact DTF particles by sieving. Separation of matrix and particles is important because it allows for the determination of how much of each is in the radially-deconsolidated annular volume.

The selected approach to achieve these goals is a modified version of the deconsolidation process previously developed for hot cell work on AGR-1 fuel compacts, coupled to a rotational deconsolidation process designed for HTGR fuel pebbles. The deconsolidation process is reliant on decomposition of the graphite matrix by intercalation - the separation of graphite layers by the electrolytic insertion of nitrous oxide compounds. Rotation of a fuel pebble or compact such that only a small fraction of the outer edge is exposed to nitric acid and an electrical current at any given moment results in a gradual, radiallysymmetric deconsolidation from the outside in via the intercalation process.

\section{GRAPHITE INTERCALATION}

In pure nitric acid, graphite intercalation proceeds by a three-stage chemical reaction [Forsman, et al. 1978]. In the first stage, nitric acid self-dissociates to produce water and two nitrous oxide ions:

$$
2 \mathrm{HNO}_{3} \leftrightarrow \mathrm{H}_{2} \mathrm{O}+\mathrm{NO}_{3}^{-}+\mathrm{NO}_{2}^{+} .
$$

\footnotetext{
* In this report, the term "fission product" is used in a general sense to refer to all the post-fission isotopes remaining at the end of the irradiation test. These include: isotopes directly generated by the fission process, isotopes generated by neutron activation, isotopes generated by radioactive decay, and residual uranium.
} 
In the second stage, the nitrous oxide cation transfers its charge to the carbon anode, oxidizing the graphite matrix (here, oxidizing refers to removing valence electrons from the carbon atoms) and evolving gaseous nitrogen dioxide:

$\mathrm{NO}_{2}^{+}+\mathrm{C} \rightarrow \mathrm{C}^{+}+\mathrm{NO}_{2}$.

Finally, in the third stage nitric acid and nitrous oxide anions infiltrate the graphite matrix between its basal planes to form a Graphite Intercalation Compound (GIC):

$$
(n C)^{+}+\mathrm{NO}_{3}^{-}+x \mathrm{HNO}_{3} \rightarrow \mathrm{C}_{n}^{+} \cdot \mathrm{NO}_{3}^{-} \cdot x \mathrm{HNO}_{3}
$$

where the GIC stage $(n)$ refers to the number of basal planes between singular layers of intercalated nitrate in the GIC structure, and $\mathrm{x}$ is between 3 and 4.5 [Forsman, et al. 1978]. If the stage of the GIC is greater than 1, excess nitrate anions will be produced by the dissociation step which are not consumed in the intercalation step. These excess anions may be consumed in an acidic solution by the formation of dinitrogen tetroxide, which will have the effect of converting the nitric acid solution from clear to yellow [Forsman, et al. 1978]:

$2 \mathrm{NO}_{3}^{-}+4 \mathrm{H}^{+}+2 e^{-} \rightarrow \mathrm{N}_{2} \mathrm{O}_{4}+2 \mathrm{H}_{2} \mathrm{O}$.

While the above sequence correctly represents graphite intercalation in pure nitric acid, the presence of water in dilute nitric acid disrupts the process by changing the dominant nitric acid dissociation mechanism to one that produces nitrate anions and hydronium:

$\mathrm{HNO}_{3}+\mathrm{H}_{2} \mathrm{O} \leftrightarrow \mathrm{NO}_{3}^{-}+\mathrm{H}_{3} \mathrm{O}^{+}$.

Lacking a nitrous oxide cation, the graphite matrix must be externally oxidized to give the graphite a net positive charge, allowing nitrate anions to diffuse in and intercalate the graphite [Skaf, et al. 1992]. This oxidation may be accomplished by the application of an electrical current using the graphite as the anode, with a threshold voltage that increases as the concentration of nitric acid decreases. Concurrently, electrons are consumed at the cathode, producing gaseous nitric oxide [Skaf, et al. 1992]:

$\mathrm{HNO}_{3}+3 \mathrm{H}^{+}+3 \mathrm{e}^{-} \rightarrow 2 \mathrm{H}_{2} \mathrm{O}+\mathrm{NO}$ (gas).

Finally, the graphite matrix oxidized by the applied voltage and nitrous oxide anions produced by nitric acid dissociation react to produce the intercalated graphite:

$(n C)^{+}+\mathrm{NO}_{3}^{-}+x \mathrm{HNO}_{3} \rightarrow \mathrm{C}_{n}^{+} \cdot \mathrm{NO}_{3}^{-} \cdot x \mathrm{HNO}_{3}$.

These underlying chemical reactions provide the basis to understand what is observed during radial deconsolidation of AGR compacts by graphite intercalation. In concentrated nitric acid, intercalation proceeds at relatively low voltage, excess nitrous oxide anions are consumed to produce dinitrogen tetroxide (turning the solution yellow), and only a small quantity of gas is evolved at the cathode. As the concentration of nitric acid is decreased, the voltage necessary to initiate intercalation is increased, significant quantities of nitrous oxide anions are not produced (maintaining a clear solution), and a large quantity of nitric oxide gas is evolved at the cathode.

\section{DECONSOLIDATION APPARATUS AND PROCESS DEVELOPMENT}

The starting point for the development of the radial deconsolidation apparatus was a rig originally designed to rotate fuel pebbles for deconsolidation, shown in Figure 1. This rig was modified to allow the much smaller fuel compacts to be mounted and used as the basis for further experimental development to determine the most effective method for compact radial deconsolidation. Compacts were epoxied to a 
mounting rod using a centering vee-block, as shown in Figure 2, to allow the compact to be chucked to the rotary motor of the deconsolidation apparatus.

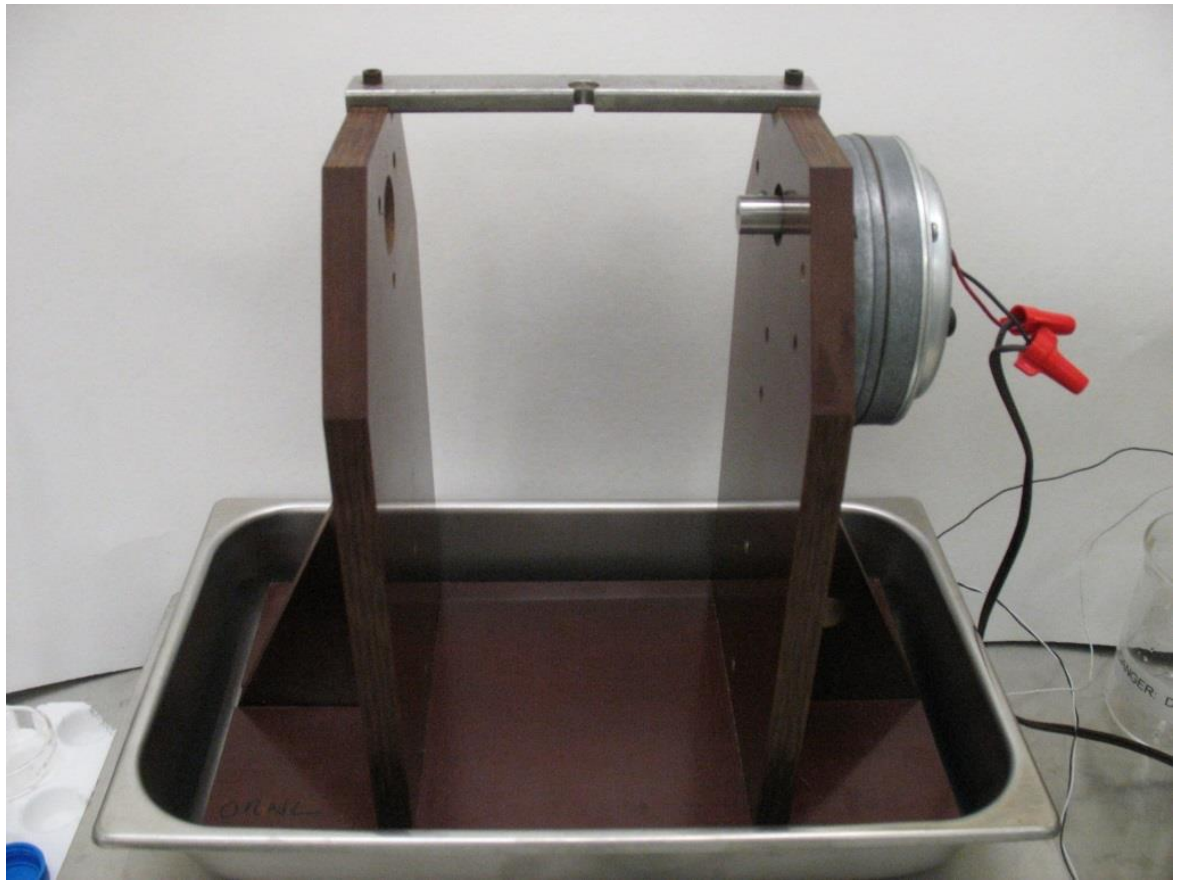

Figure 1. Radial deconsolidation rig originally used for fuel pebble deconsolidation.

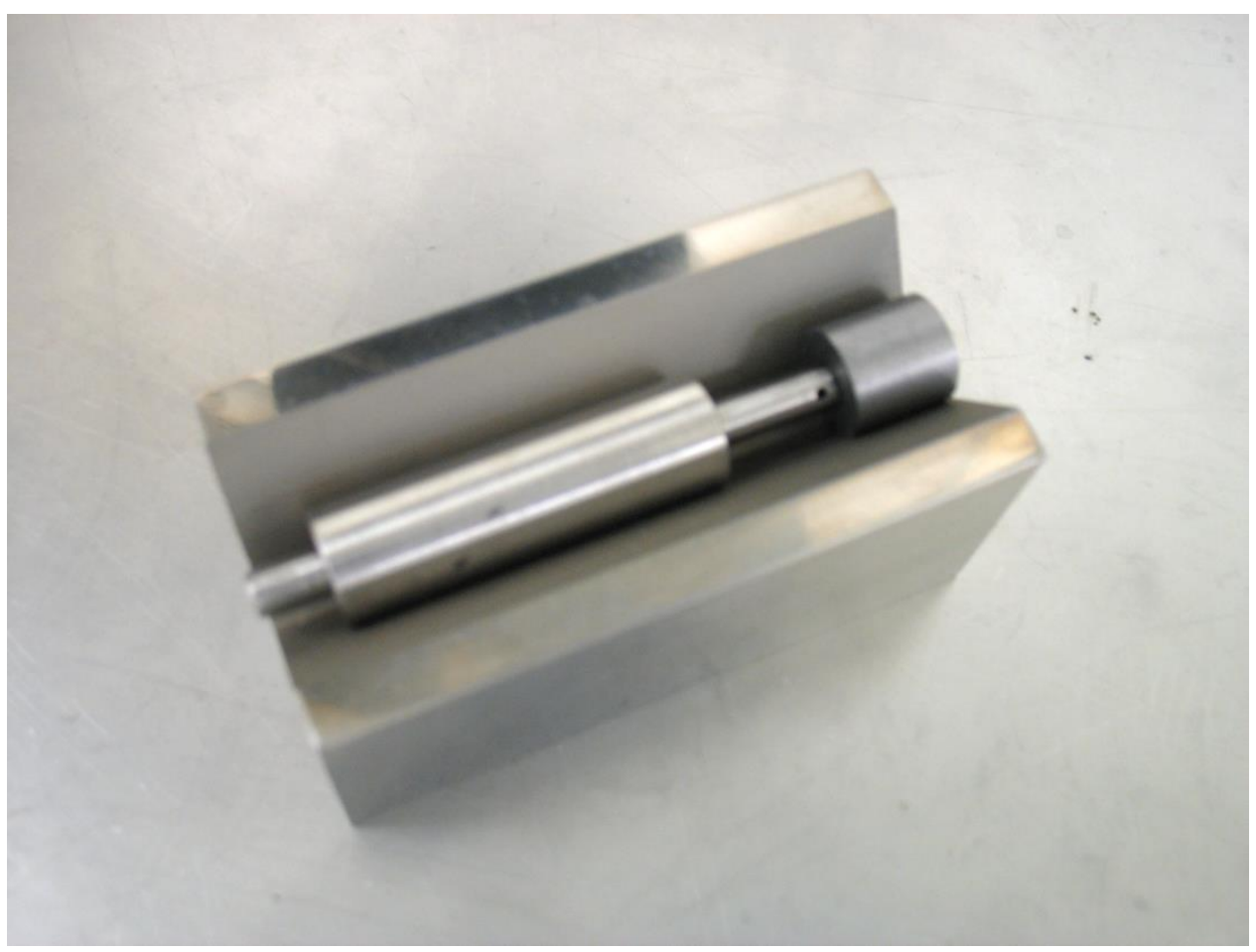

Figure 2. Compact epoxied to mounting rod in centering vee-block. 


\subsection{Application of acid}

Two basic approaches were considered for the application of acid to the compact: stream and static bath. In the stream method, shown schematically in Figure 3, a stream of flowing nitric acid would contact the rotating compact close to the anode. Acid would be collected and recirculated by a pumping system and deconsolidated material would be gathered in a Soxhlet thimble. This approach would offer the advantage of naturally breaking up and washing deconsolidated debris from the compact surface with the acid stream. Initial tests of the stream deconsolidation process showed that this method was viable. However, further development was abandoned in favor of the static bath method, which appeared to be simpler to control and implement in a remote hot cell operation.

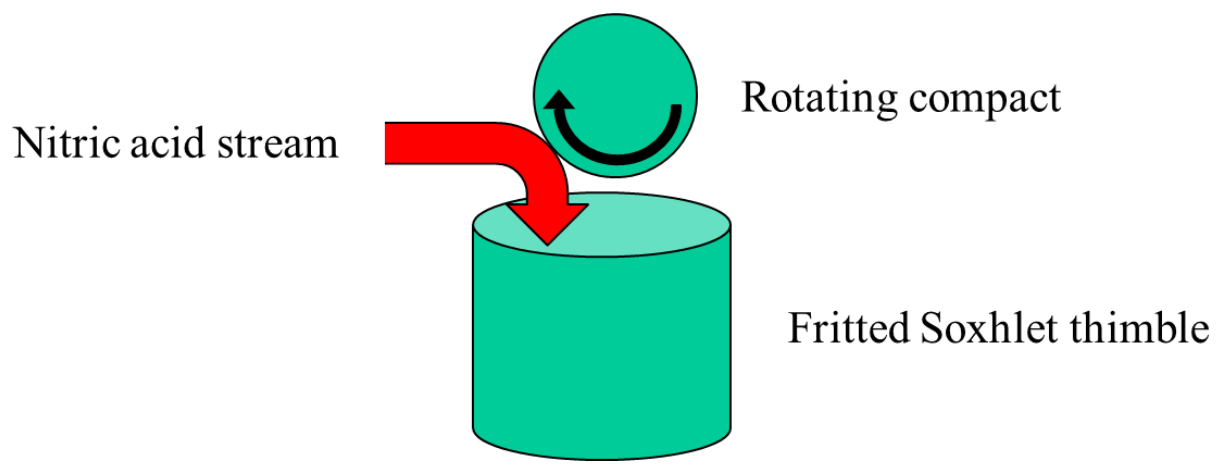

Figure 3. Schematic of the stream deconsolidation method.

In the static bath method nitric acid is contained in a beaker in which the rotating compact is partially submerged, as shown in Figure 4. While the static bath method does not provide natural rinsing of the compact surface, it has the advantage of being much simpler to implement. Early test runs to radially deconsolidate compacts using a static bath of nitric acid showed that the approach worked well, and that debris could be effectively removed from the surface by the presence of a mesh screen lightly pressed against the compact as it rotated. Given the simpler solution offered by the static bath method, this approach was selected for further development.

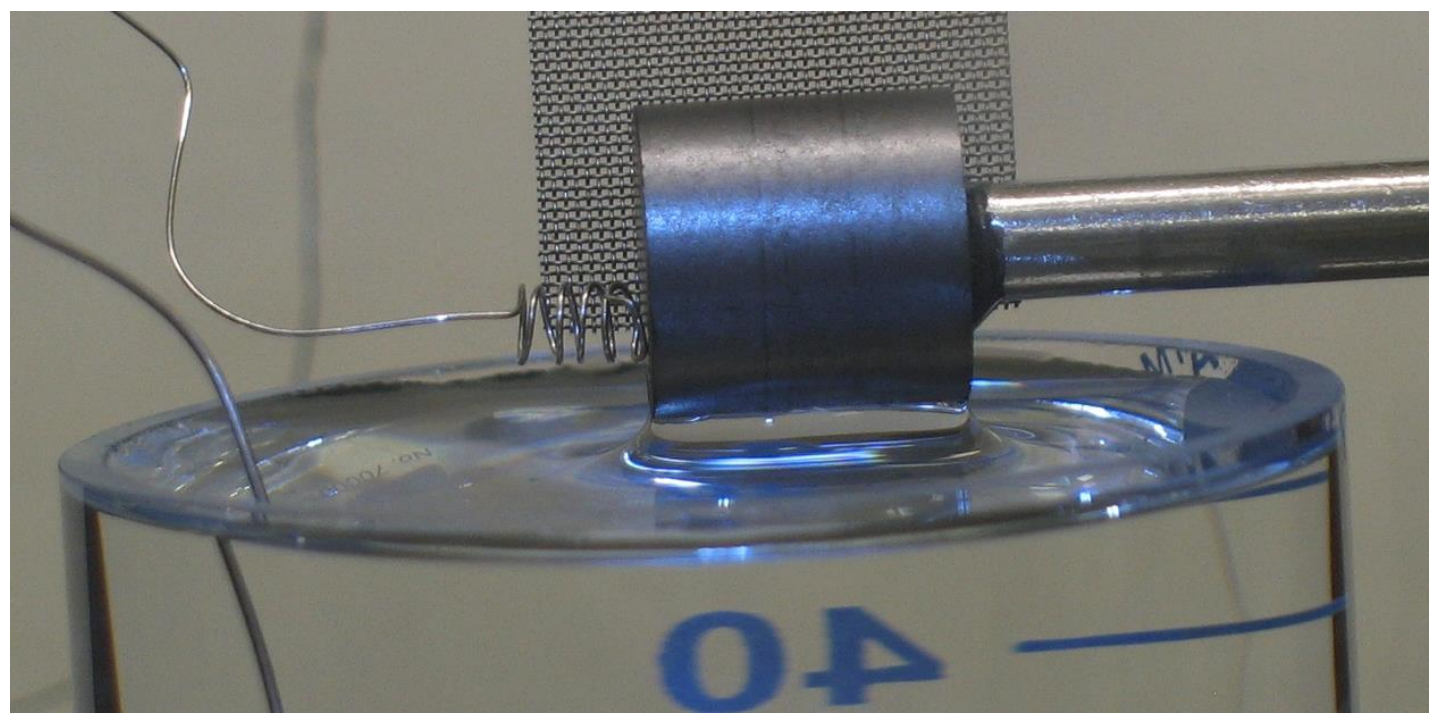

Figure 4. Early deconsolidation test using a static bath with an insulated mesh screen. 


\subsection{Removal of deconsolidated material}

From the first tests of the radial deconsolidation method it was clear that some form of deconsolidated material removal would be necessary to prevent massive buildup on the compact surface. Two methods for deconsolidated material removal were tested: a brushing screen and ultrasonic vibration. The initial implementation of a brushing screen was moderately successful so long as the screen was non-reactive with nitric acid. It was found that stainless steel screens were suitable so long as the screen was not a part of the electrolytic circuit, and that a suitably light force could be applied simply by bending the screen. While this approach was functional, it was non-ideal in that the force applied by the bent screen was nonreproducible between runs, which impacted both the deconsolidation rate and the size distribution of the deconsolidated material.

The use of ultrasonic vibration as an alternative deconsolidated material removal method was tested by submerging the beaker containing the nitric acid bath in a small ultrasonic bath. The test was unsuccessful, as the ultrasonic waves were incapable of effectively removing deconsolidated material from the compact. Instead, the compact expanded rapidly into a low-density agglomerate of matrix and particles. It is possible that more powerful ultrasonic vibration may be capable of effectively removing deconsolidated material; however, given the uncertainty and the expense involved it was decided to focus on the use of an improved screen brushing system.

The final deconsolidated material removal system consisted of a screen attached to a solid backing plate which swung into contact with the compact on a weighted lever arm, as shown in Figure 5. The solid backing on the screen ensured that uniform contact was made along the length of the compact, while the application of force by a weighted arm allowed for reproducible manipulation of the brushing force. Free body diagram analysis of the rotating screen holder in contact with the compact as the compact is deconsolidated showed that variation in force over the span of the deconsolidation is minor, with a difference between minimum and maximum force of approximately $1 \%$.

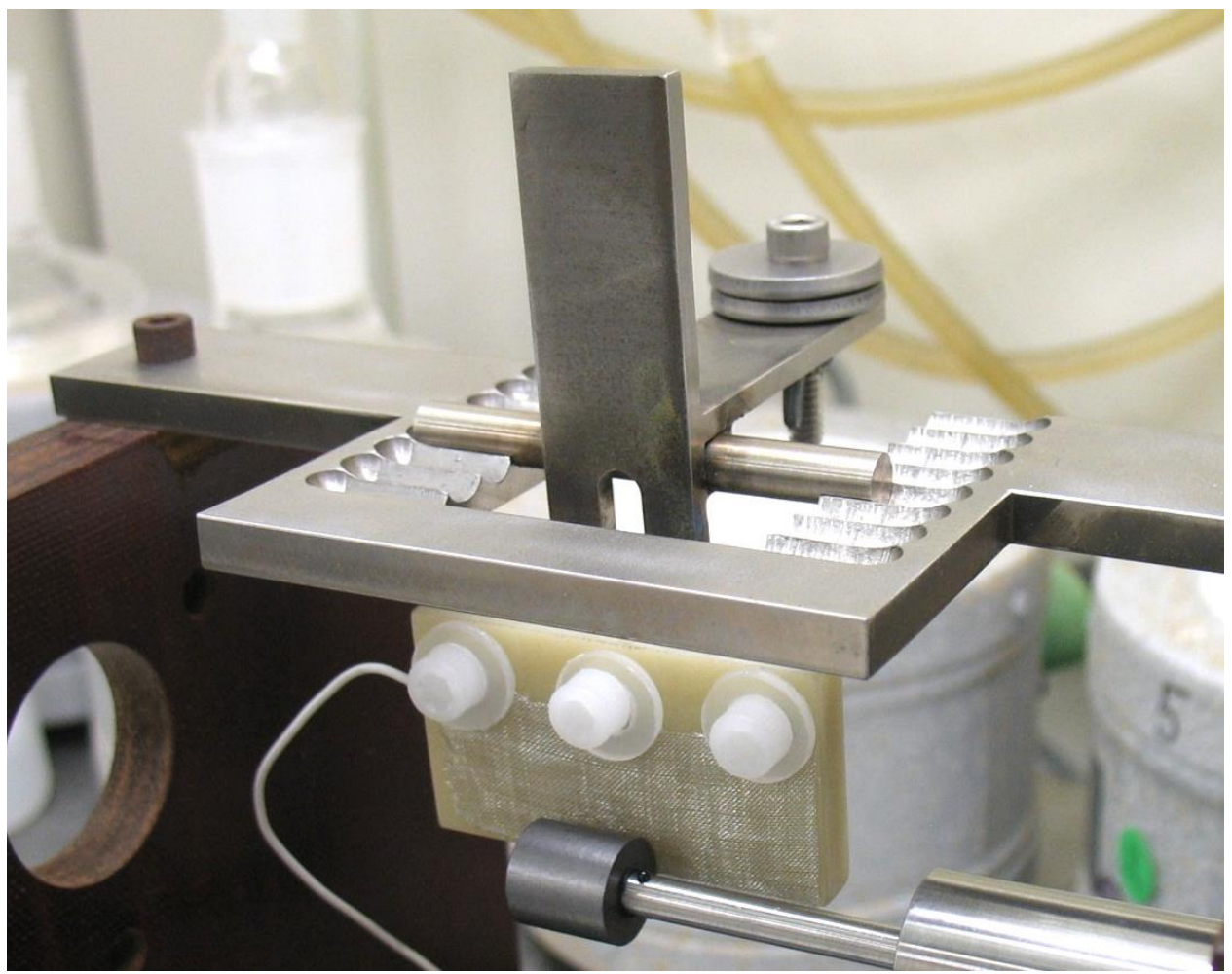

Figure 5. Deconsolidated material removal screen held in place against compact prior to deconsolidation. 


\subsection{Application of current}

Electrolytic intercalation of graphite requires that an electrical current be applied to the compact for deconsolidation. As such, three potential methods to apply current were considered: through a wire in contact with the compact end, through a screen or foil in contact with the compact side, and through the mounting rod by which the compact was rotated. The wire approach was considered initially, but once a conductive epoxy was found to allow current application through the mounting rod it was abandoned, since both approaches apply current through the end of the compact but the wire approach requires an extra component to be kept in place.

Significant testing was performed using the mounting rod to apply current to the compact; however, it was found that this method commonly resulted in undesirable irregularities during deconsolidation. During the first fraction of deconsolidation there was typically an induction period in which no material was deconsolidated followed by a burst of rapid deconsolidation of large flakes of matrix. In addition, in the later stages, it was common for the compact to taper significantly towards the unmounted end and to eventually break into two axial sections. These phenomena were attributed to the electrical current distribution within the compact which resulted from current entering through an axial end and exiting through the outer perimeter. Since intercalation of graphite in dilute nitric acid occurs only in the presence of an electrical current, the reaction within the compact followed the path of the electrical current. This lead to intercalation occurring simultaneously on the outer annulus of the compact, where it is desired, and in the inner regions, where it is not.

When electrical current was applied through the brushing screen in contact with the side of the compact, all three of the irregular deconsolidation issues associated with mounting rod current application were remedied. This may be understood based on the current distribution in the compact associated with this method - a regular annulus along the full length of the compact. Since the screen is subjected to both nitric acid and electrical current, it must be made from an inert yet conductive material, such as platinum.

\section{FINAL DECONSOLIDATION PROCESS}

The following process for radial deconsolidation of AGR-3/4 compacts was the final result of experimentation with various different approaches. It has been found to meet both primary objectives

described above by removing annular volumes of material with consistent and accurately-measureable radial boundaries, while also producing relatively-clean, undamaged TRISO particles and fine matrix debris.

\subsection{Sample preparation}

Before deconsolidation compacts were weighed and measured to establish a baseline reference for each. Compact weight was measured using a Mettler-Toledo XP 504 scale, accurate to the greater of either $\pm 0.0002 \mathrm{~g}$ or $\pm 0.0002 \%$. Compact height and diameter were each measured based on the average of a series of three measurements using calipers accurate to $0.01 \mathrm{~mm}$.

After weighing and measurement, one end of the compact was attached to a mounting rod using a centering vee-block to ensure axial alignment. AA-CARB 61 conductive epoxy manufactured by Atom Adhesives was used to allow a voltage to be applied to the compact through the mounting rod for final axial deconsolidation. Once the epoxy was dry, the attached rod and compact were reweighed to determine the mass of the rod and epoxy. 


\subsection{Radial deconsolidation}

The experimental setup for radial deconsolidation is given in Figure 6, including all the labeled features described below. Compacts were attached to the rotary motor (A) by the attached mounting rod. At the start of each fraction a polystyrene vial (B) was filled to the brim with nitric acid and placed on a heightadjustable platform beneath the compact. The vial was seated in the center of a wide petri dish to catch any material which overflowed the edge of the vial during deconsolidation. The platform was then adjusted upwards until contact was made between the compact and the surface of the nitric acid, then slightly lowered such that a meniscus bridged the gap between the compact and the nitric acid. Once the bridging meniscus was formed, rotation of the compact was initiated and controlled using the rotary motor power supply. Contact with the acid through this raised meniscus helped to minimize the contact area during radial deconsolidation.

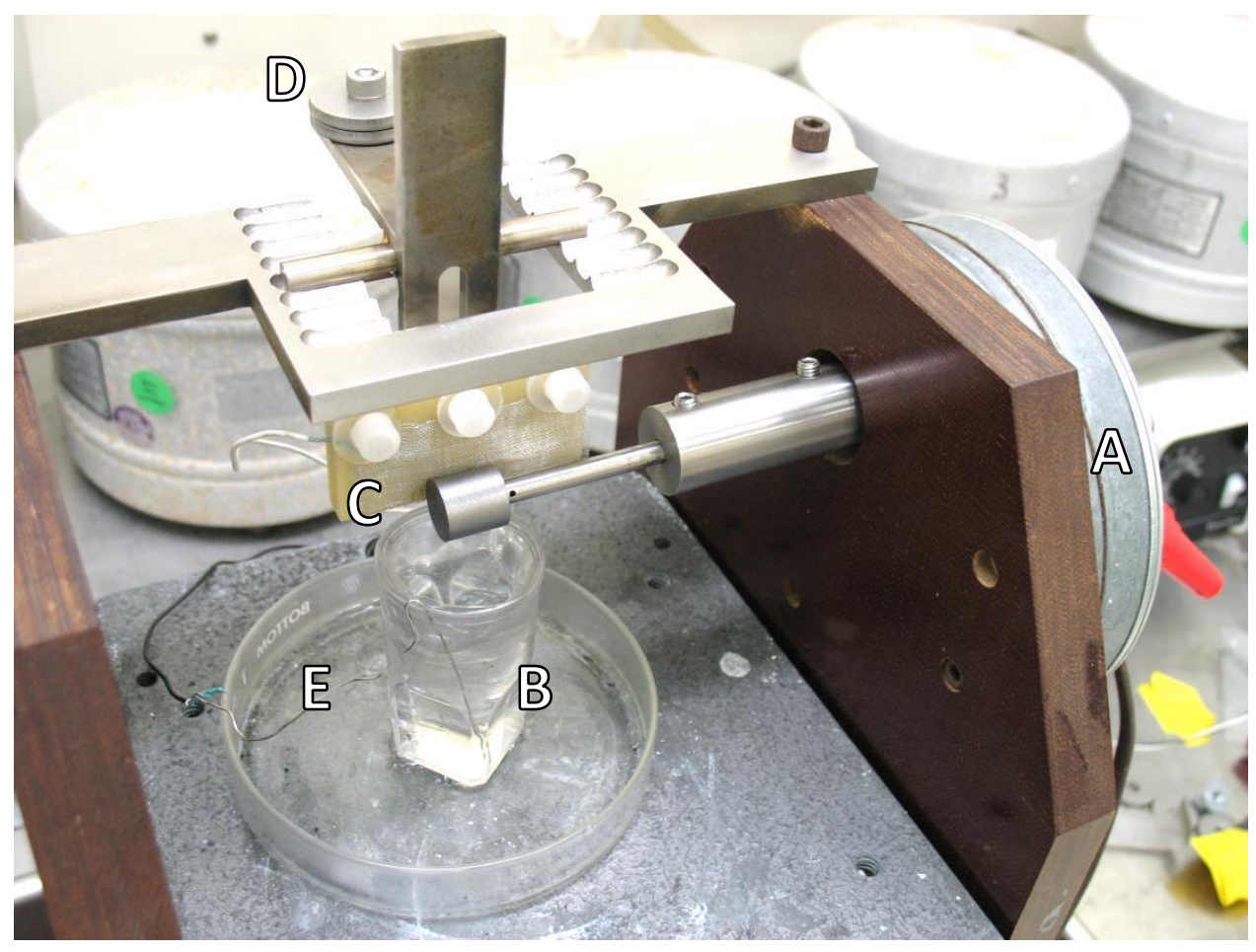

Figure 6. Compact mounted on the final apparatus ready for deconsolidation.

During rotation, a positive potential was applied to the compact through a platinum screen (C). This screen was pressed against the compact by a lever and fulcrum system with weights (D) that could be adjusted to control the screen force. An electrochemical cell was formed by inserting a platinum wire (E) into the nitric acid to serve as the cathode while the wetted-portion of the compact acted as the anode. The electrical circuit was controlled by a power source set to run in fixed current mode.

As described previously, the electrolytic deconsolidation proceeded by a three step process consisting of nitric acid dissociation with water, concurrent anodic oxidation of the compact and cathodic reduction of the aqueous solution, and infiltration of the graphite basal planes by nitrate anions and nitric acid:

$$
\begin{aligned}
& \mathrm{HNO}_{3}+\mathrm{H}_{2} \mathrm{O} \leftrightarrow \mathrm{NO}_{3}^{-}+\mathrm{H}_{3} \mathrm{O}^{+}, \\
& \mathrm{HNO}_{3}+3 \mathrm{H}_{3} \mathrm{O}^{+}+3 \mathrm{e}^{-} \rightarrow 5 \mathrm{H}_{2} \mathrm{O}+\mathrm{NO}(\text { gas }), \\
& (n \mathrm{C})^{+}+\mathrm{NO}_{3}^{-}+x \mathrm{HNO}_{3} \rightarrow \mathrm{C}_{n}^{+} \cdot \mathrm{NO}_{3}^{-} \cdot \mathrm{XNNO}_{3} .
\end{aligned}
$$


Each deconsolidation step was continued until the desired fraction of compact material had been removed. Between each deconsolidation step, the electrochemical and rotary power supply systems were switched off and the platform holding the nitric acid vial was lowered. The contents of the reaction vial were transferred to a labeled centrifuge tube, initially by pipette to minimize material loss, then with a water rinse to ensure all material was transferred. The brushing screen was also rinsed with water between fractions and this material was added to the centrifuge tube. The reaction vial was then refilled with fresh nitric acid for the next step in the radial deconsolidation. At the beginning, end, and periodically throughout the deconsolidation of each fraction, short video recordings were taken of the rotating compact for use in optical measurement of compact diameter.

\subsection{Compact core deconsolidation}

After all desired annular volume fractions of deconsolidated material have been gathered, the remaining core of the compact can be axially deconsolidated. To perform axial deconsolidation, the mounting rod attached to the compact was removed from the rotary motor coupling and suspended vertically above a clean nitric acid vial on an adjustable height platform. As in the radial deconsolidation step, the circuit cathode was a platinum wire inserted into the vial of nitric acid; however, the anodic current was applied directly to the compact mounting rod, rather than through a screen. The setup for a compact core ready for axial deconsolidation is shown in Figure 7.

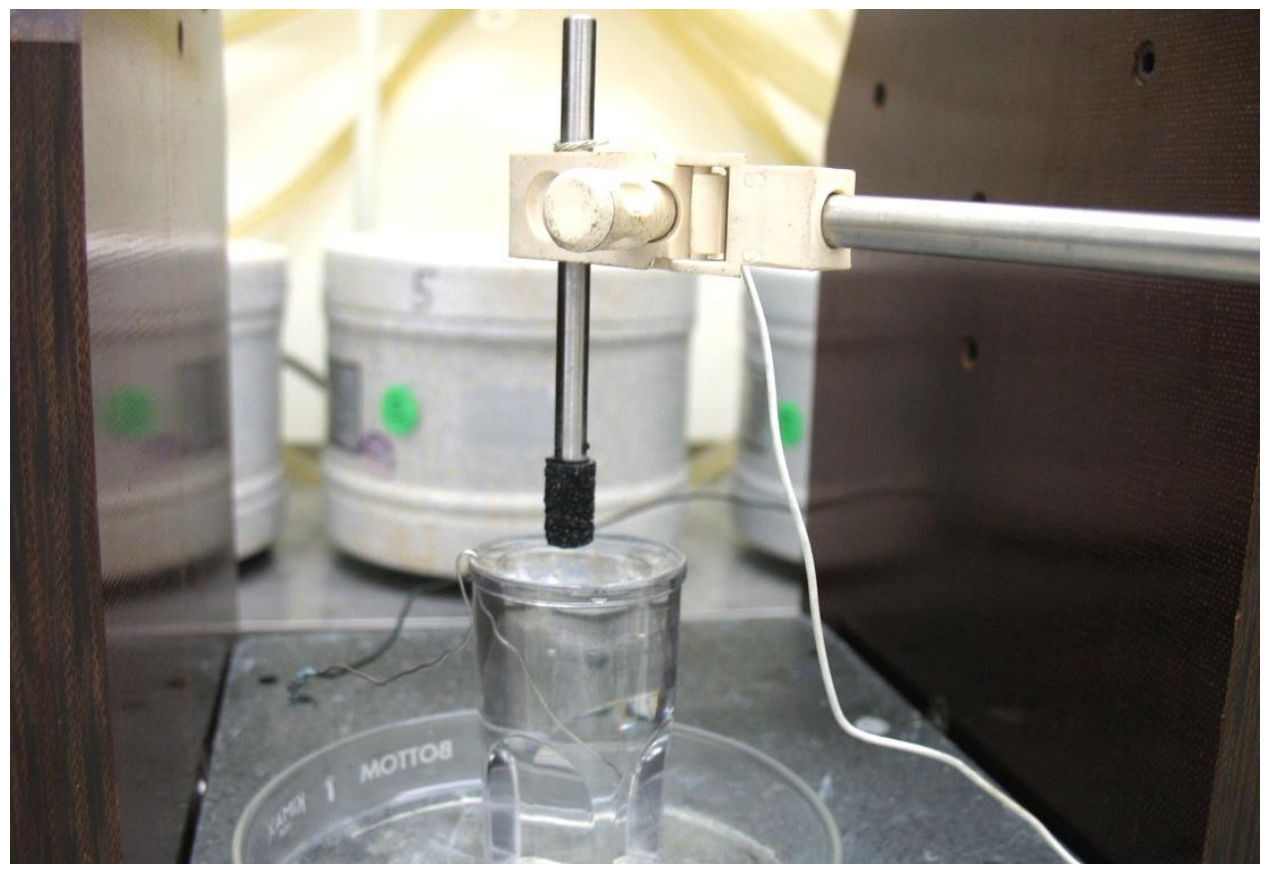

Figure 7. Setup for axial deconsolidation of the compact core.

The compact core was then deconsolidated by gradually raising the platform holding the vial of nitric acid to submerge the tip of the compact. As the tip of the compact deconsolidated, the platform was progressively raised to submerge the next segment until the compact core was fully deconsolidated. This process has been found to produce significantly coarser deconsolidated material than the preceding radial deconsolidation steps, due to the absence of the brushing action from the screen. Methods to further refine this material by subjecting the debris to further electrolytically-assisted intercalation were tested with mixed success, and it was concluded that digestion in concentrated nitric acid will be necessary if finer material is required. 


\subsection{Deconsolidated material analysis}

Once a compact was fully deconsolidated, the material gathered in each fraction was analyzed to assess the performance of the apparatus and test parameters. This analysis was specifically developed to quantify the quality of the deconsolidated material produced during testing, and would be replaced by an appropriate analysis sequence to measure post-irradiation isotope distribution in practice; however, some of the preparatory steps may be transferable.

The first step for analysis of each fraction of deconsolidated material was rinsing off residual nitric acid by sequentially centrifuging and decanting. Fractions were placed in centrifuge vials and spun down for 5 minutes at 4000 RPM to settle all deconsolidated material to the bottoms of the vials. Excess liquid was then decanted from each vial to reach the minimum quantity of liquid possible without loss of solid material. Vials were then refilled with approximately $15 \mathrm{~mL}$ of $\mathrm{NERL}^{\mathrm{TM}}$ high-purity water. Water rinsing was performed twice for each fraction to dilute the residual nitric acid, then twice more with methanol to replace the aqueous solution with a more volatile one to speed drying.

Once the rinsing process was complete, each fraction was sieved using a sieving stack consisting of 1000$\mu \mathrm{m}, 600-\mu \mathrm{m}$, and $250-\mu \mathrm{m}$ sieves. These sieves were selected to separate agglomerates larger than 1000 $\mu \mathrm{m}$, TRISO particles $(\sim 800-\mu \mathrm{m}$ diameter $)$, DTF particles $(\sim 390-\mu \mathrm{m}$ diameter $)$, and fine matrix debris smaller than $250 \mu \mathrm{m}$. Deconsolidated material on the sieves was gently agitated with methanol to break up loosely agglomerated material. Excess methanol from rinsing was gathered in the bottom pan, along with the fine material, and decanted using an aluminum weigh pan. The three sieves and the weigh pan containing the fine material were dried in an oven at $75^{\circ} \mathrm{C}$ for 15 minutes.

The dried material from each sieve was weighed to develop a size distribution of deconsolidated material. The fine material that passed through all three sieves was weighed directly in the aluminum weigh pan in which it was decanted, as any dry transfer of this material would entail significant losses due to its size. TRISO particles recovered from the $600-\mu \mathrm{m}$ sieve were separated from loose matrix by hand tabling. These particles were reweighed and imaged for particle counting and average particle weight determination.

\section{OPTICAL MEASUREMENT SYSTEM}

One of the requirements of the radial deconsolidation process is that the radial boundaries associated with each fraction of material gathered be well known. However, this measurement is more difficult than is initially apparent due to minor variations in the compact surface during deconsolidation and the potential for breaking the compact with mechanical measurements. Several measurement systems were considered and tested, including sets of caliper measurements along the compact length, volume measurement via immersion, and back calculation of volume based on fraction weights and densities. Ultimately it was concluded that optical measurement through digital video of the deconsolidation process was the best option as it provides sufficient accuracy and precision while also being relatively straightforward to implement.

\subsection{MATLAB script description}

Conversion of video recording of the deconsolidation process into measurements of the compact radius was accomplished using a MATLAB script. The script first analyzes videos frame-by-frame using a fiducial mark to determine the number of frames per rotation of the compact. The user is then able to specify how many frames per rotation of the compact should be analyzed. The user additionally inputs the known diameter of the mounting rod, which serves as a built-in image calibration, and draws approximate contours around the rod and the compact on an initial frame. Examples of the user-drawn contours for the fiducial mark, mounting rod, and compact are shown in Figure 8. 

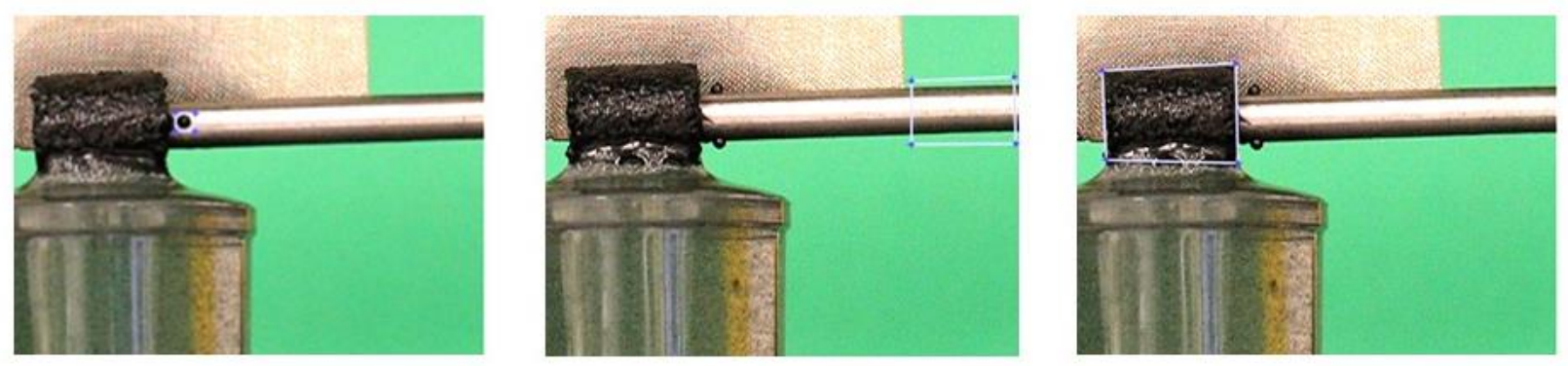

Figure 8. User selected fiducial mark (left), starting rod contour (center), and starting compact contour (right).

Once these initial steps are completed, the script automatically measures the compact diameter at the correct number of evenly spaced frames for each rotation. The initial contours for both the compact and the mounting rod are refined for each frame to fit the image. The initial compact contour is refined using the Chan-Vese edge finding algorithm with a strong bias toward smoothing and a slight bias toward contraction. These settings were found to possess the best balance between capturing the minor variations in the compact surface and avoiding inclusion of dark areas outside the compact. The rod contour is refined using a color edge finding algorithm which takes advantage of the green screen used during video recording.

Any tilt in the image is corrected by testing the refined rod contour from angles of $-5^{\circ}$ to $+5^{\circ}$ in increments of $0.1^{\circ}$ to find the image angle which minimizes the deviation of the rod from horizontal. Once the ideal angle is found, the image is rotated to make the rod horizontal and the top and bottom of the rod are found based on the rotated rod contour. Finally, the rotated compact contour is used to find the top of the compact. The radius of the compact is determined based on the average vertical distance from the top of the compact to the center of the rod, using the user-input diameter of the rod to scale the image.

After compact measurement has been completed for each frame to be analyzed, a linear correction is applied to remove the minor dependence of measured diameter on apparent tilt. A least squares fit is used to find the slope of measured radius versus apparent tilt, which is then used to adjust each measured radius based on the difference between its apparent tilt and the average tilt across all frames. This adjustment reduces the standard deviation in measured diameter between frames while having no impact on the average measured radius across all frames. Data for each frame analyzed, including frame number, rotation, radius, tilt, scale, and tilt corrected radius, as well as the average radius for all frames, is output to an Excel file. In addition, an image is saved for each frame analyzed with the top, bottom, and center of the rod marked by red lines and the compact contour shaded blue, as shown in Figure 9. 


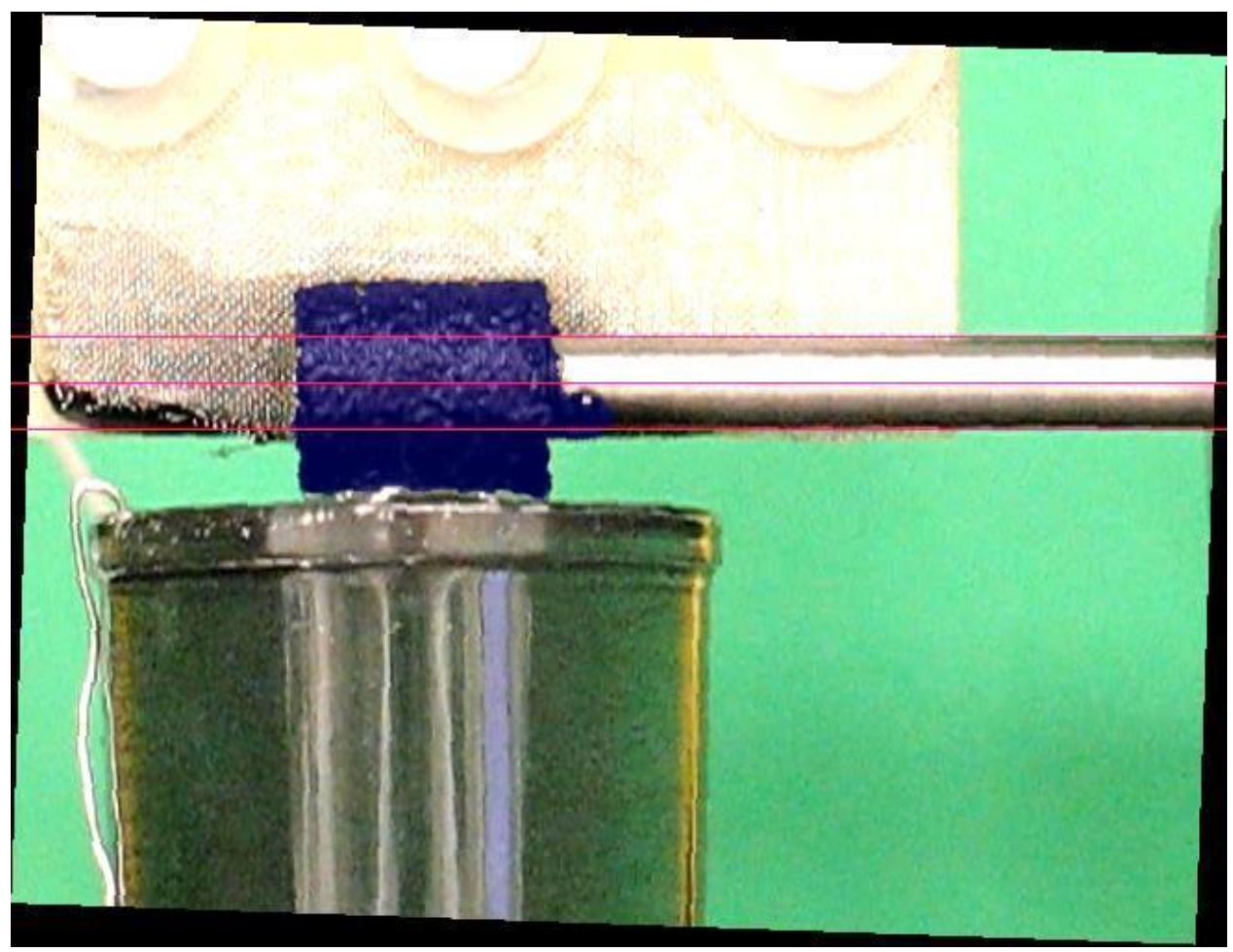

Figure 9. Marked output image from MATLAB.

\subsection{Accuracy of optical measurements}

The accuracy of the optical measurement method was tested by comparing the results from video recording of rotating compacts before deconsolidation to caliper measurements of compact diameter. These results were found to be in strong agreement with one another. A typical compact was measured to have a radius of $6.16 \mathrm{~mm}$ based on a series of three caliper measurements along the length of the compact. The same compact was found to have an average radius of $6.17 \mathrm{~mm}$ with a standard deviation of $0.09 \mathrm{~mm}$ based on optical measurement, a difference of less than $0.2 \%$ and well within the accuracy of the caliper used to measure the compact and mounting rod.

In fact, the optical measurement system was found to be robust enough to reliably capture both the slight axial runout in the compact during rotation (due to inevitable slight misalignment between the motor, mounting rod, and compact) and the gradual reduction in radius due to deconsolidation. As shown in Figure 10, as the compact rotates on the mounting rod there is a consistent pattern of increasing and decreasing radius as a function of rotational position. The range in radii measured at each rotational position is a combination of the reduction in true compact radius with time due to deconsolidation and stochastic error in the optical measurement process. 


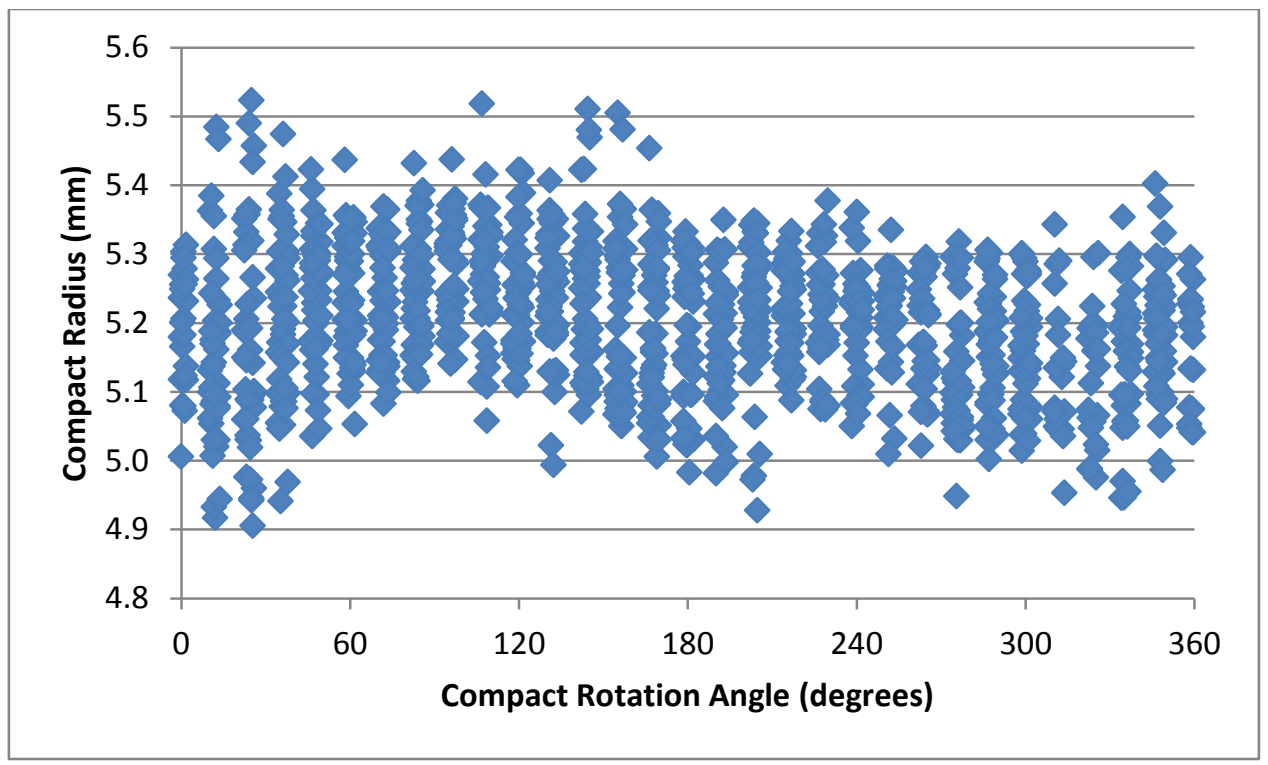

Figure 10. Rotational dependence of apparent compact radius on rotation angle (vertical spread is due to radial deconsolidation and stochastic measurement error).

The reduction in compact radius with time due to deconsolidation is shown for the same data set plotted as a function of time instead of compact rotation in Figure 11. The trend toward reduced compact radius with time is noticeable but slight, relative to the spread of the data, which is due to both the axial runout of the compact and stochastic error in the optical measurement process. Both sources of spread in the data may be mitigated by averaging across each full rotation of the compact, as shown in Figure 12.

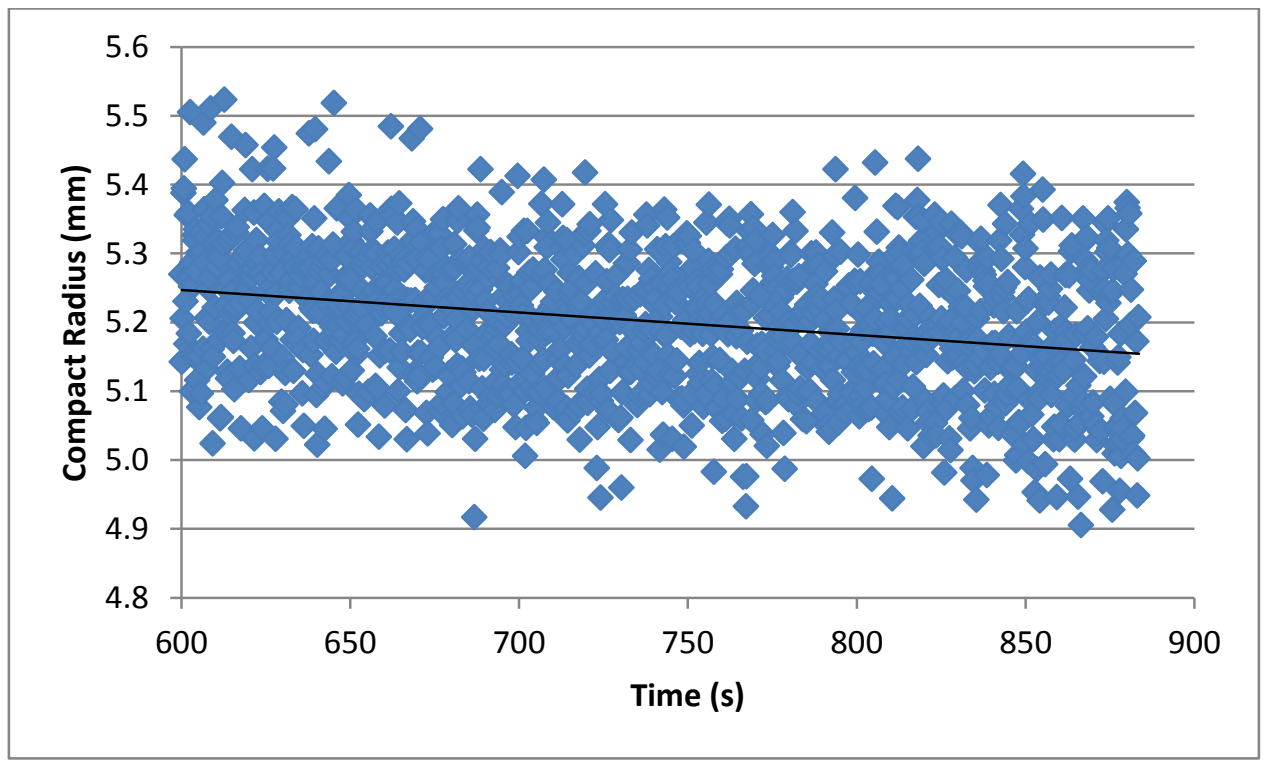

Figure 11. Gradual reduction of compact radius over time due to deconsolidation (vertical spread is due to axial runout and stochastic measurement error). 


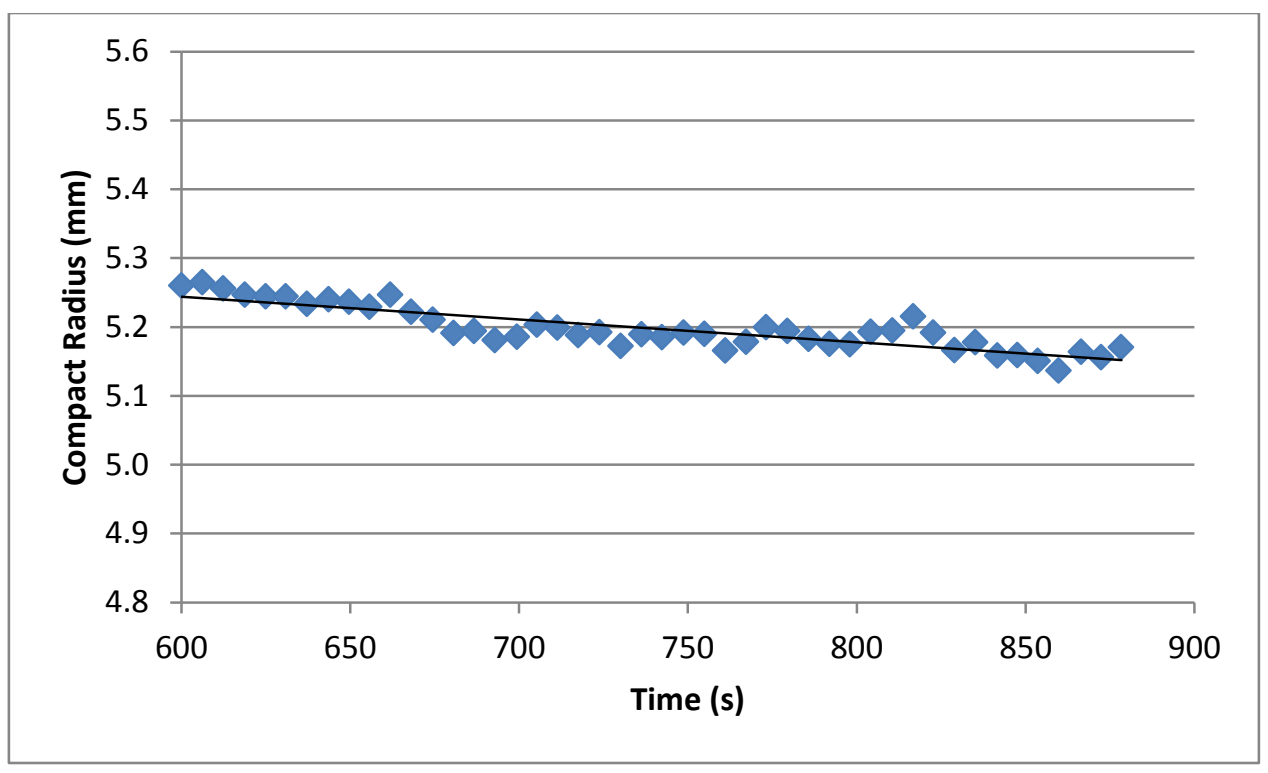

Figure 12. Reduction in compact radius over time smoothed out by averaging over each full rotation.

The change in compact radius as a function of time was generally linear after averaging across each full rotation, however, the first fraction for each compact included an early spike over the first couple minutes of deconsolidation, as shown in Figure 13. This apparent increase in compact radius was attributed to the flaking of matrix material from the outer surface of the compact. The first stages of deconsolidation were characterized by the gradual cracking of the initially smooth compact surface, which resulted in the protrusion of small flakes of matrix material. The eventual removal of these attached flakes and the initiation of steady-state deconsolidation was marked by the start of an approximately linear deconsolidation rate. Based on this effect, optical measurement of compact radius is inaccurate during the first stage of deconsolidation until the initial spike in radius has resolved.

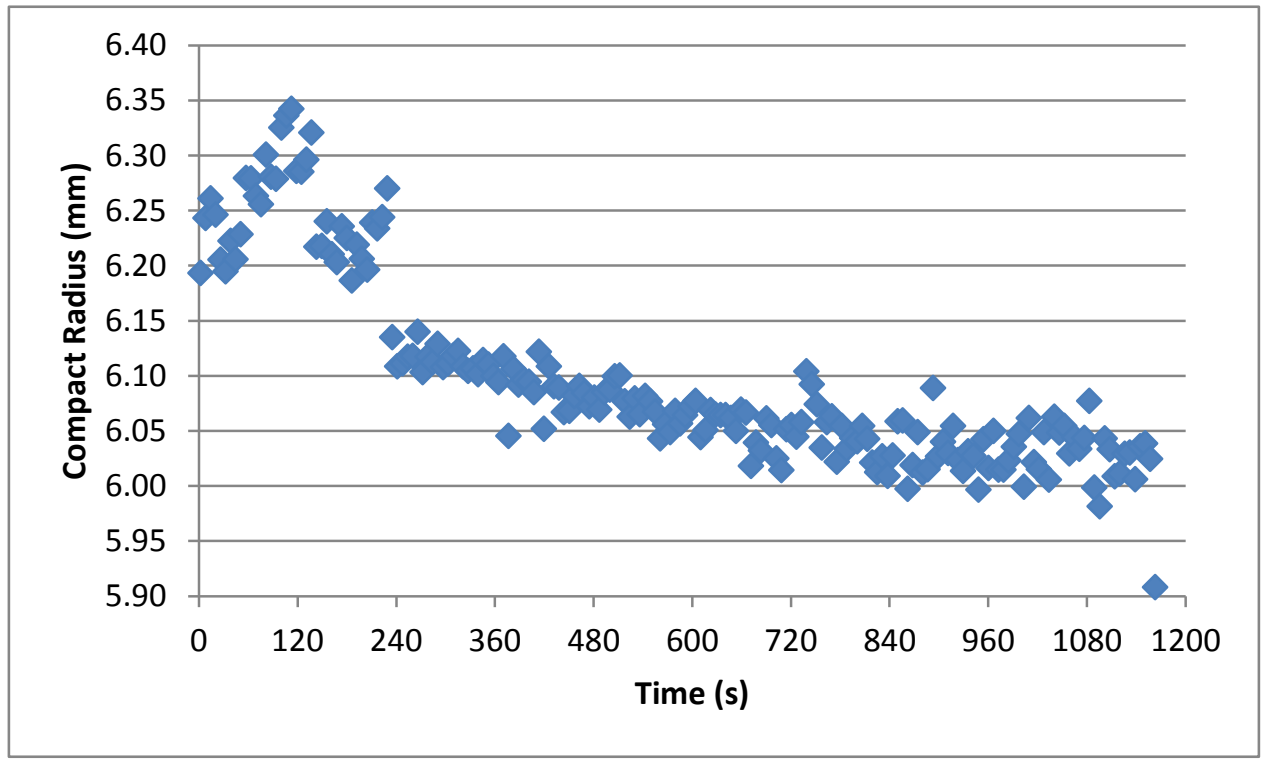

Figure 13. Compact radius during initial deconsolidation demonstrating surface flaking effect. 


\section{PARAMETER DEVELOPMENT}

Testing has been performed to determine the optimal parameter set to be used for radial deconsolidation. Parameters under consideration include the nitric acid concentration, the applied current, and the force applied by the screen to the side of the compact. The effects of these parameters on the deconsolidation were quantified based on the size distribution of the deconsolidated material, the amount of residual matrix attached to the deconsolidated TRISO particles, and the rate of deconsolidation.

The initial test matrix of parameters considered included $6 \mathrm{~N}$ and $4 \mathrm{~N}$ nitric acid with an applied current of $250 \mathrm{~mA}, 500 \mathrm{~mA}$, and $750 \mathrm{~mA}$. The ranges of these parameters were selected based on initial scoping tests of the deconsolidation process. Concentrated (70\%) nitric acid was used in some initial tests, and was found to result in a different chemical process than more dilute $6 \mathrm{~N}(26 \%)$ and $4 \mathrm{~N}(18 \%)$ nitric acid. The concentrated acid solution turned from clear to yellow, indicating the production of dinitrogen tetroxide during intercalation, while the dilute acid solutions remained clear and produced large amounts of nitrous oxide gas at the cathode. In addition, compacts deconsolidated in concentrated nitric acid were found to consistently fracture across their center during the later stages of deconsolidation, prematurely ending the final fraction. Parametric testing was thus focused on the more dilute nitric acid. It is important to note that an effective lower limit on acid concentration is imposed by the increased voltage required to induce intercalation as acid concentration decreases and the empirical limit based on prior experience of $12 \mathrm{~W}$ of applied power to preclude damaging TRISO particles during deconsolidation. The conditions tested were well below this limit, as the maximum electrical power applied to the compacts was less than $4 \mathrm{~W}$.

The limit on applied power also informed the selection of applied currents to test. For the apparatus used it was found that intercalation in $4 \mathrm{~N}$ and $6 \mathrm{~N}$ nitric acid did not initiate below $200 \mathrm{~mA}$, and reached a practical rate around $250 \mathrm{~mA}$. This was selected as the lower bound, with $500 \mathrm{~mA}$ and $750 \mathrm{~mA}$ selected as higher currents keeping in mind that the applied power increased with the square of the applied current.

The results from the initial test matrix for $6 \mathrm{~N}$ and $4 \mathrm{~N}$ nitric acid at each current are shown in Figure 14 and Figure 15. No clear trend in the rate of deconsolidation or the amount of residual matrix on deconsolidated particles was found; however, there was a clear trend for both the $4 \mathrm{~N}$ and $6 \mathrm{~N}$ nitric acid in the size distribution of deconsolidated matrix as a function of applied current. In both cases the fineness of the deconsolidated matrix material increased significantly from the $250 \mathrm{~mA}$ case to the $500 \mathrm{~mA}$ case, then slightly from the $500 \mathrm{~mA}$ case to the $750 \mathrm{~mA}$ case. The reduction in deconsolidated matrix size with increasing current is consistent with previously reported shifts to lower stage GICs with increasing current (Skaf, et al., 1992). As the GIC stage decreases, the smaller number of graphite layers between intercalating nitrate anion layers naturally results in finer deconsolidated matrix. The reduced impact of additional current appears to be a saturation effect, which is likely related to the minimum size which can be reached before intercalated matrix material is detached from the anode (the compact), stopping the intercalation process. 


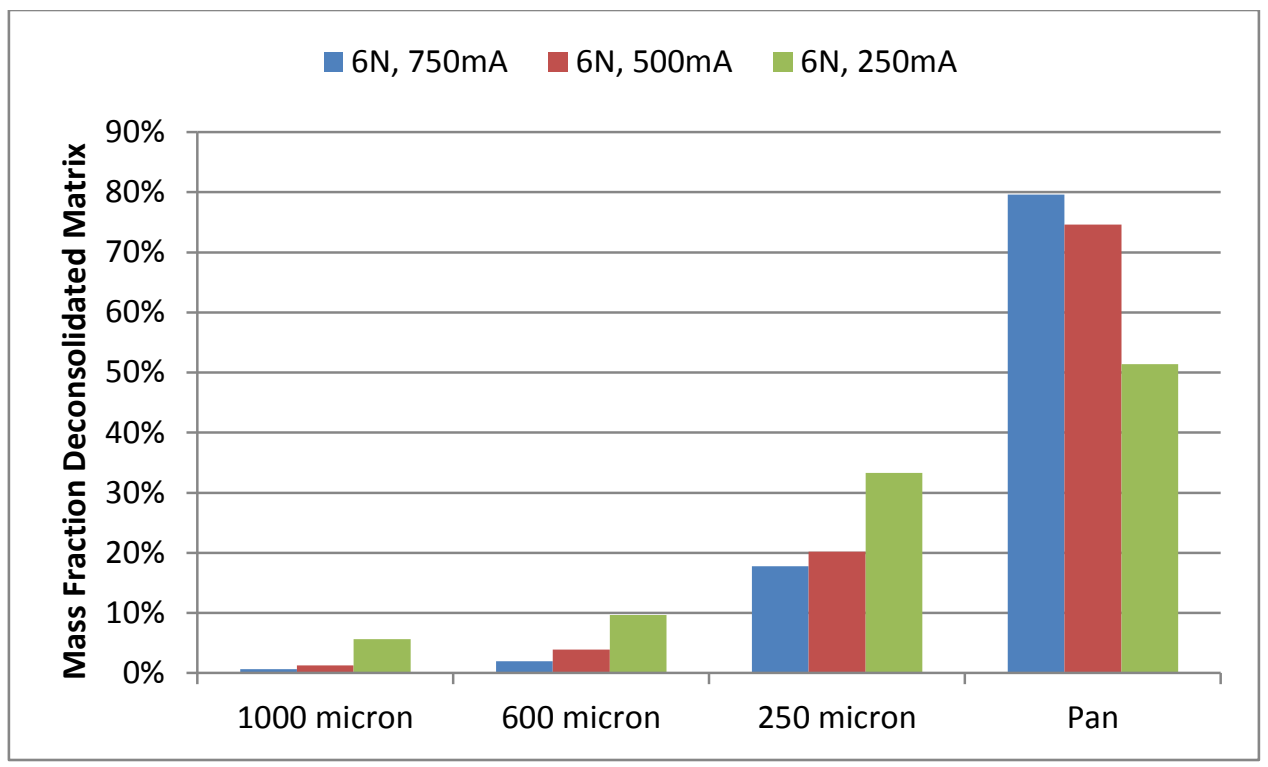

Figure 14. Size distribution of deconsolidated matrix from tests varying current with $6 \mathrm{~N}$ nitric acid and $200 \mathrm{mN}$ applied force.

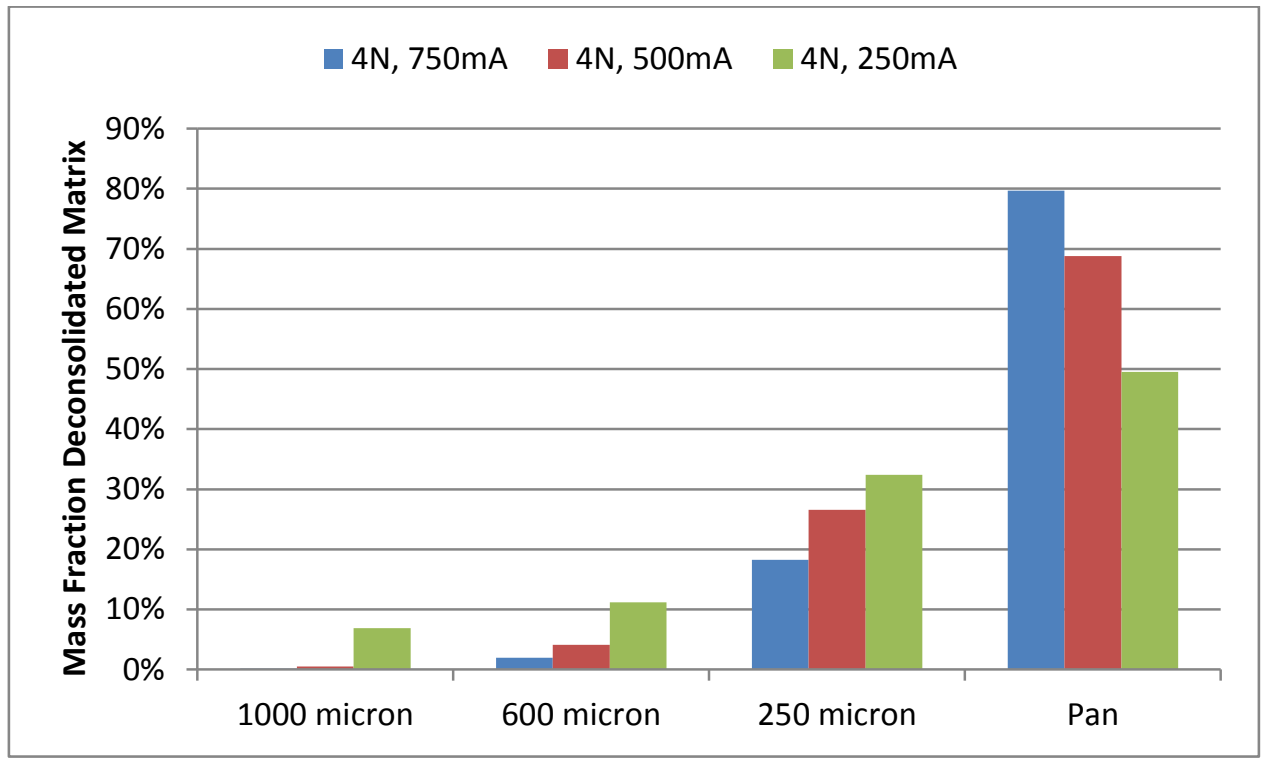

Figure 15. Size distribution of deconsolidated matrix from tests varying current with $4 \mathrm{~N}$ nitric acid and $200 \mathrm{mN}$ applied force.

Based on the results from the initial test matrix, it was decided to focus further testing on $4 \mathrm{~N}$ nitric acid with $750 \mathrm{~mA}$ applied current. The selection of $750 \mathrm{~mA}$ current was clear based on the preceding results. The selection of $4 \mathrm{~N}$ over $6 \mathrm{~N}$ nitric acid was based on two factors. First, the rate of deconsolidation was slightly higher for tests with $4 \mathrm{~N}$ acid than those with $6 \mathrm{~N}$ acid. Second, given only a slight difference in results between the two, it is generally preferable to use a lower concentration of acid for cost and safety reasons. Thus, the secondary test matrix considered the effect of varying the brushing force applied by the mesh screen to the side of the compact while holding acid concentration and current constant at $4 \mathrm{~N}$ and $750 \mathrm{~mA}$. The brushing force was varied by changing the weight on the lever arm of the brushing system (D in Figure 6). A free-body diagram analysis of the brushing system with the known weights and dimensions of its components was used to calculate the approximate force applied to the side of the compact as a function of the lever arm weight. 
The effects of the brushing force on deconsolidated matrix size, residual matrix on TRISO particles, and the rate of deconsolidation were clearly shown by the test results. As shown in Figure 16, the relative quantity of deconsolidated matrix in the finer sieves increased with decreasing force. This effect is sensible, given that a lower brushing force allows deconsolidating matrix to remain in contact with the compact longer, allowing more time for intercalation of the graphite to proceed, while a higher force may dislodge layers of partially deconsolidated material.

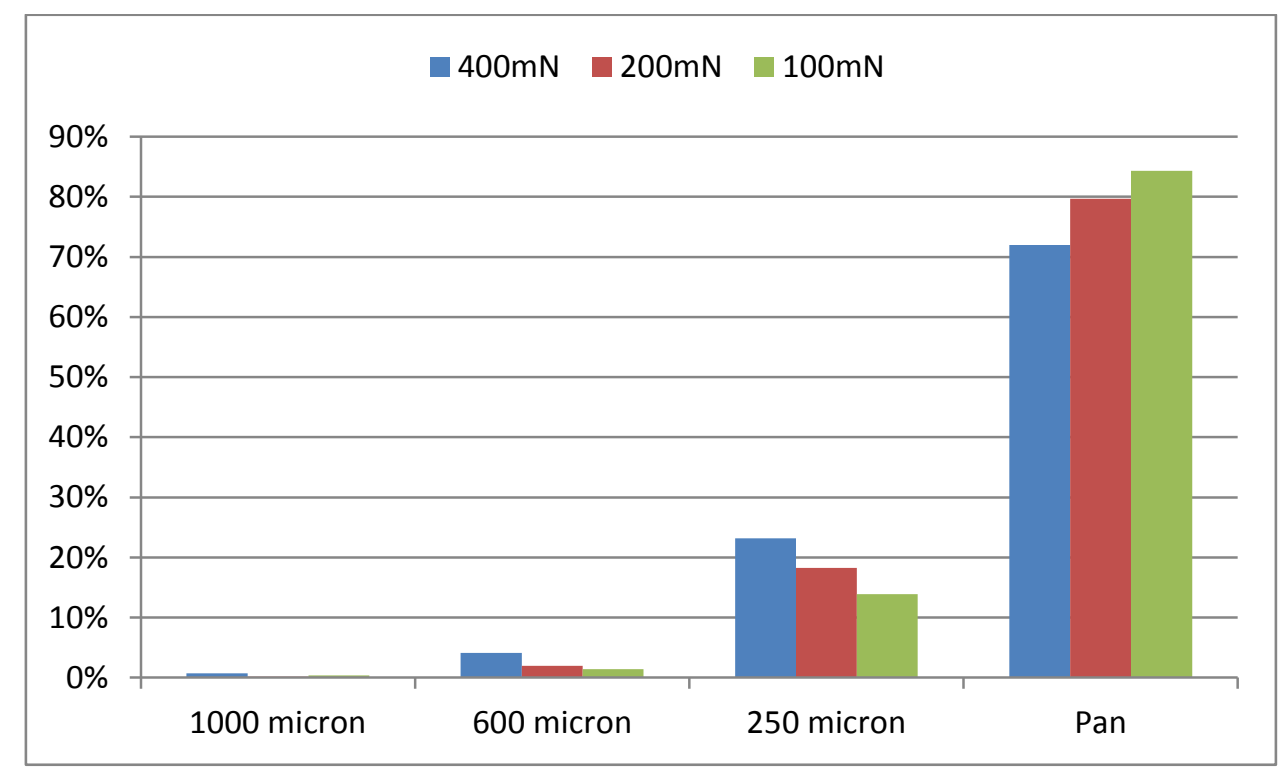

Figure 16. Size distribution of deconsolidated matrix from tests varying force with $4 \mathrm{~N}$ nitric acid and $750 \mathrm{~mA}$ current.

While the average fineness of the deconsolidated matrix was best at the lowest applied force, the amount of residual matrix on the deconsolidated TRISO particles and the rate of deconsolidation were best at the highest applied force. As shown in Figure 17, the fractional weight of residual matrix on deconsolidated particles, as measured by comparing the average deconsolidated particle weight to the known initial particle weight, increased as the applied brushing force decreased. As shown in Figure 18, the rate of deconsolidation decreased as the applied brushing force decreased. Both of these effects are reasonable given that a higher applied brushing force would have resulted in increased abrasion of the compact surface by the mesh screen.

Based on the objectives of the project, the results with a $100 \mathrm{mN}$ brushing force are the most promising. The reduced rate of deconsolidation with low force is acceptable, given that the deconsolidation of a compact will only require $\sim 2-3$ hours at that rate. While the increased degree of residual matrix on the particles under reduced force is undesirable, the increased fraction of deconsolidated matrix below $600 \mu \mathrm{m}$ is a counterbalancing desirable factor as it will allow easier hot cell separation of deconsolidated matrix and particles. Given that even at the lowest force the residual matrix is less than $0.5 \%$ of the weight of the particles, this is an acceptable tradeoff. 


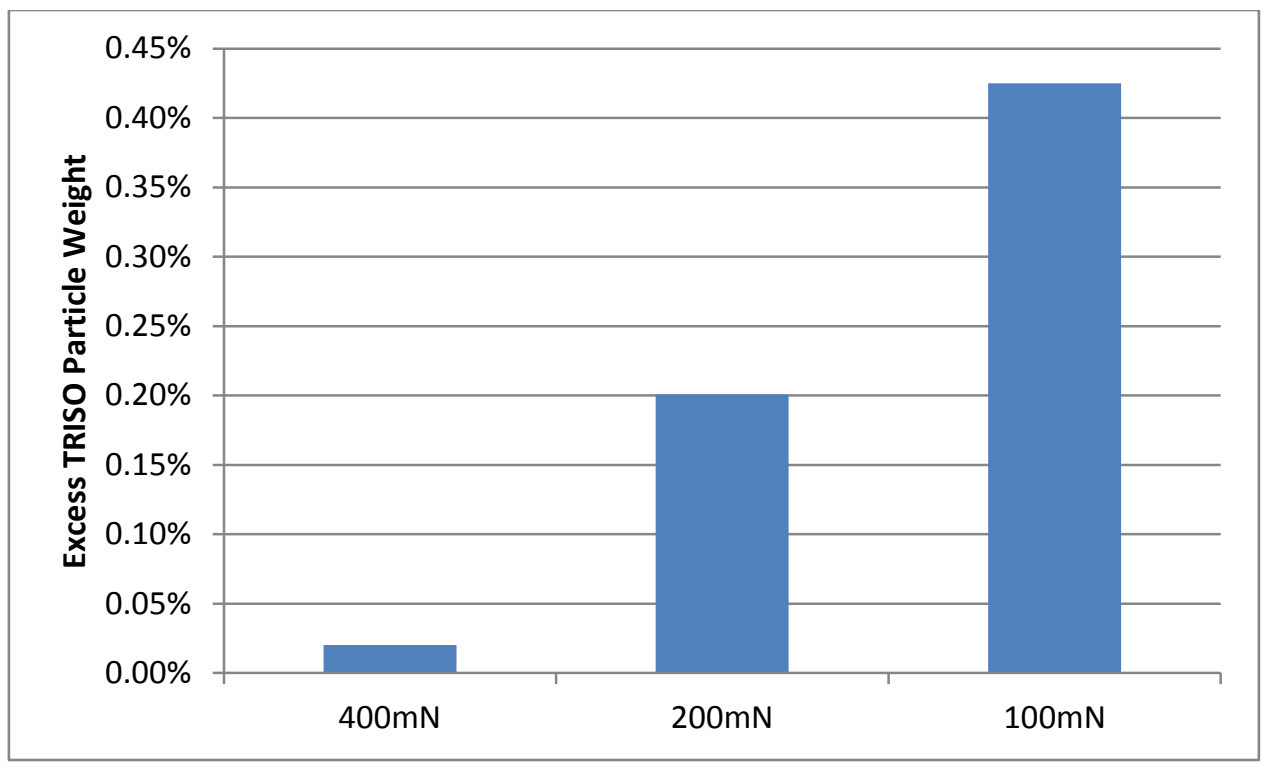

Figure 17. Residual matrix material on TRISO particles deconsolidated with variable brushing force in $4 \mathrm{~N}$ nitric acid with $750 \mathrm{~mA}$ of current.

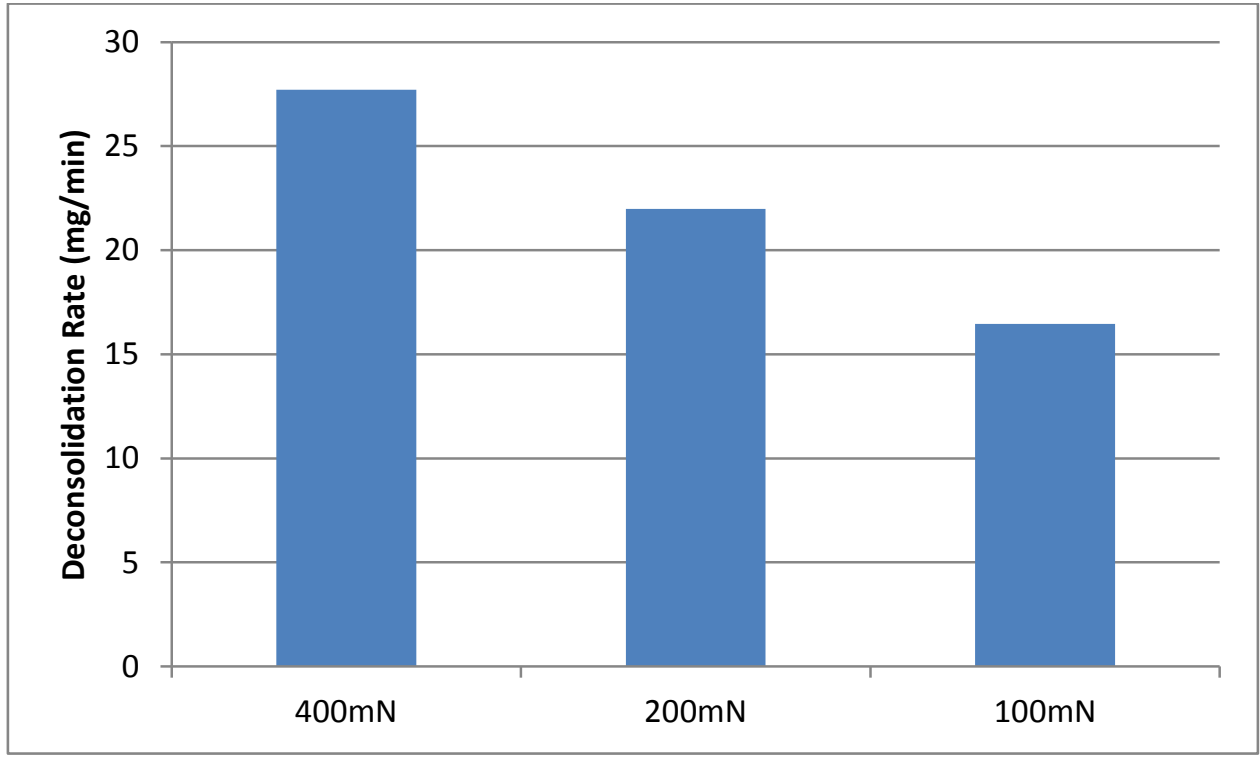

Figure 18. Rate of deconsolidation in $4 \mathrm{~N}$ nitric acid with $750 \mathrm{~mA}$ of current with variable brushing force.

\section{RECOMMENDATIONS FOR IMPLEMENTATION}

Based on the results of this work an effective radial deconsolidation process may be implemented for hot cell use with irradiated AGR-3/4 compacts. It is recommended that an apparatus similar to the one developed in this project be used, with possible modifications to allow partial immersion of the compacts without filling the nitric acid container to the brim. Based on the parametric study which was completed, operating conditions of $4 \mathrm{~N}$ nitric acid with an applied current of $750 \mathrm{~mA}$ and an applied brushing force of $100 \mathrm{mN}$ are recommended, however, these results were based on un-irradiated compacts, and may require modification for irradiated compacts. 
The necessary steps for hot cell installation of a radial deconsolidation apparatus at ORNL for use with irradiated AGR-3/4 compacts have been considered and are as follows:

- Determine whether suitable image resolution for optical measurements may be obtained via a camera exterior to the hot cell. If not, it will be necessary to place a camera inside the hot cell or use a special lens.

- Consult with hot cell operators regarding further optimization of the radial deconsolidation apparatus to simplify the system for use with hot cell manipulators.

- Build new radial deconsolidation apparatus for insertion into the hot cell.

- Perform hot cell shakedown test of radial deconsolidation apparatus using a non-irradiated compact to verify operability of the apparatus and accuracy of optical measurements.

- Modify deconsolidation parameters as necessary to adapt process to irradiated compacts.

The first of these steps has already been completed, as testing with a Sony Turboshot camera mounted to the exterior of a hot cell window was found to produce images of adequate resolution for optical measurements of the radial deconsolidation process. A test image of two objects of known size was found to produce an error of less than $2 \%$ when using one object to calculate the size of the other. Due to the yellow coloring of the hot cell windows, image analysis will be limited to the red and green color channels, suggesting the use of either red or green backgrounds to assist in automated edge detection. 


\section{REFERENCES}

Petti, D.A., J.T. Maki, J.D. Hunn, P.J. Pappano, C.M. Barnes, J.J. Saurwein, S.G. Nagley, J.M. Kendall, and R.R. Hobbins. 2010. "The DOE Advanced Gas Reactor Fuel Development and Qualification Program." JOM 62(9): 62-66.

Hunn, J.D., R.A. Lowden, J.H. Miller, B.C. Jolly, M.P. Trammell, A.K. Kercher, F.C. Montgomery, and C.M. Silva. 2012. "Fabrication and Characterization of Driver Fuel Particles, Designed-to-Fail Fuel Particles, and Fuel Compacts for the US AGR-3/4 Irradiation Test." Paper HTR2012-3-026 in Proceedings of the 6th International Topical Meeting on High Temperature Reactor TechnologyHTR 2012, Tokyo, Japan, October 28-November 1, 2012. Also published in Nuclear Engineering and Design 271: 123-130.

Hunn, J.D., M.P. Trammell, and F.C. Montgomery. 2011. Data Compilation for AGR-3/4 Designed-toFail (DTF) Fuel Compact Lot (LEU03-10T-OP2/LEU03-O7DTF-OP1)-Z. ORNL/TM-2011/124, Revision 0. Oak Ridge, Tennessee: Oak Ridge National Laboratory.

Kercher, A.K., B.C. Jolly, F.C. Montgomery, G.W.C. Silva, and J.D. Hunn. 2011. Data Compilation for AGR-3/4 Designed-to-Fail (DTF) Fuel Particle Batch LEU03-07DTF. ORNL/TM-2011/109, Revision 0. Oak Ridge, Tennessee: Oak Ridge National Laboratory.

Hunn, J.D., and R.A. Lowden, Data compilation for AGR-3/4 driver coated particle composite LEU0309T. ORNL/TM-2007/019, Revision 0. Oak Ridge, Tennessee: Oak Ridge National Laboratory.

Collin, B.P. 2015. AGR-3/4 Irradiation Experiment Test Plan. INL/PLN-3867, Revision 1. Idaho Falls, Idaho: Idaho National Laboratory.

Forsman, W.C., Vogel, F.L., Carl, D.E., Hoffman, J. 1978. "Chemistry of Graphite Intercalation by Nitric Acid." Carbon 16: 269-271.

Skaf, D.W., Edwards, J.K. 1992. "Electrochemical Graphite Intercalation with Nitric Acid Solutions." Synthetic Metals 46:137-145. 